\title{
Squamous cell carcinoma of the oesophagus with choroidal metastasis
}

\author{
JOAN MULLANEY \\ National Ophthalmic Pathology Laboratory and Registry of Ireland, Royal Victoria Eye and Ear \\ Hospital, Dublin
}

The occurrence of carcinoma metastasizing to the intraocular tissues is unusual but the world literature contains reviews of large series of cases. The sites of the primary growths have been extensively documented, with the breast and lung being the commonest sources. Examination of the available literature appeared to suggest the existence of only one previous description of carcinoma in the eye secondary to an oesophageal primary growth, a surprising rarity in view of the thoracic situation of the oesophagus. Larsen (1933) described a secondary deposit in the right iris in a patient initially seen with a squamous cell carcinoma of the lower third of the oesophagus diagnosed by oesophagoscopy. Death took place 2 months after the first presentation. A squamous cell carcinoma was confirmed in autopsy iris tissue. The choroid was clinically free of tumour.

This paper describes what appears to be the first reported case of carcinoma of the oesophagus metastasizing to the choroid.

\section{Case report}

A 67-year-old man presented with a 6 months' history of dysphagia and considerable weight loss. A barium swallow showed a carcinomatous stricture in the middle third of the oesophagus (Fig. I).

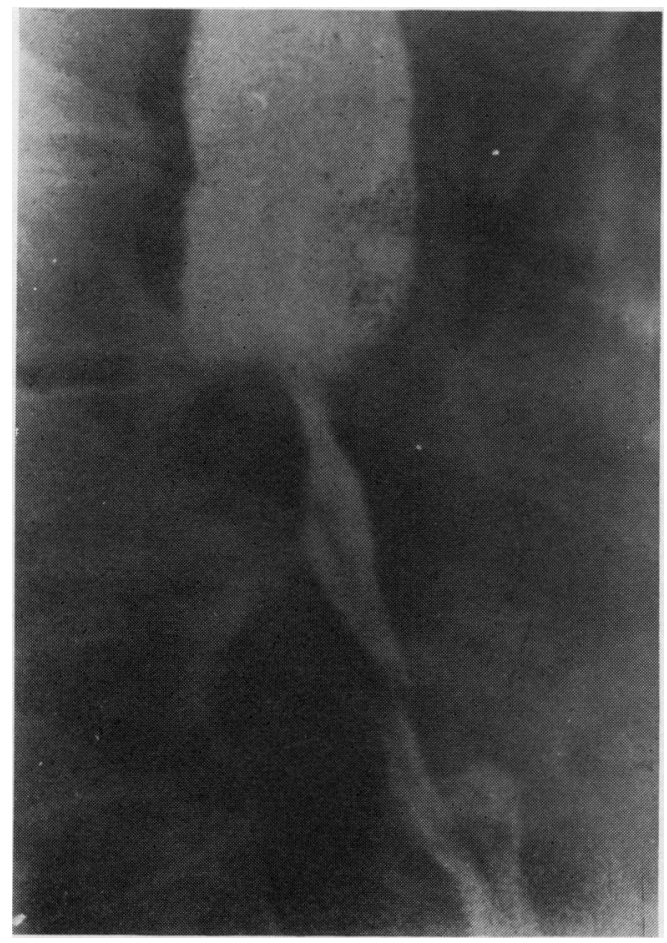

FIG. I Oblique view of barium-filled oesophagus showing stricture 
His general condition was too poor for a thoraco-abdominal operation. Laparotomy to insert a Bardon tube was unsuccessful because of the degree of stricture and a feeding gastrostomy was performed.

There was no clinical or radiological evidence of metastases at this time, but 6 months later he complained of pain in the right eye.

\section{Examination}

There was absence of transillumination, a shallow solid retinal detachment, and secondary glaucoma. Metastatic oesophageal cancer of the choroid was diagnosed and enucleation was performed.

Result

In spite of his low state of health the patient survived a further 6 months, and died a year after the laparotomy.

\section{GROSS PATHOLOGY}

The specimen consisted of a right eye measuring $24 \times 24 \times 23 \mathrm{~mm}$. with no external abnormality. Examination of the opened specimen (Fig. 2) showed massive infiltration of the superior temporal choroid by yellowish convoluted tumour tissue which extended into the ciliary processes. There was an associated flat retinal detachment.

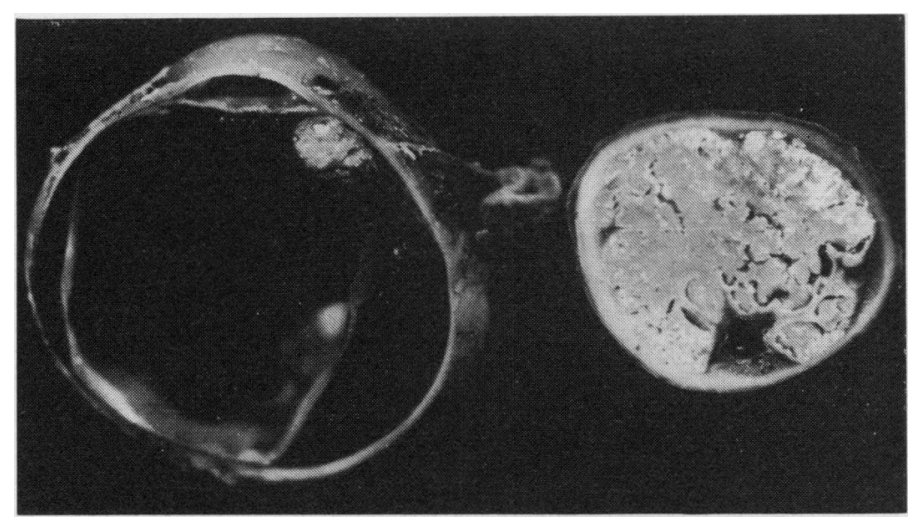

FIG. 2 Choroidal and ciliary body tumour infiltration in opened globe

HISTOLOGY

The main finding at microscopy was the presence of a well-differentiated keratinizing squamous cell carcinoma (Fig. 3) filling the choroid and extending at some levels to involve the posterior portion of the ciliary body. No scleral or extraocular infiltration was seen. The uveal tract contained scattered reactive chronic inflammatory cells. The iris and filtration angles appeared within normal limits and the optic disc and nerve were not morphologically abnormal. The retina showed secondary degenerative changes and the detached areas had underlying fluid accumulation.

\section{Summary}

Carcinoma of the oesophagus metastasizing to the eye appears to be extremely rare. This paper describes what appears to be the first reported case of such an occurrence in the choroid. 


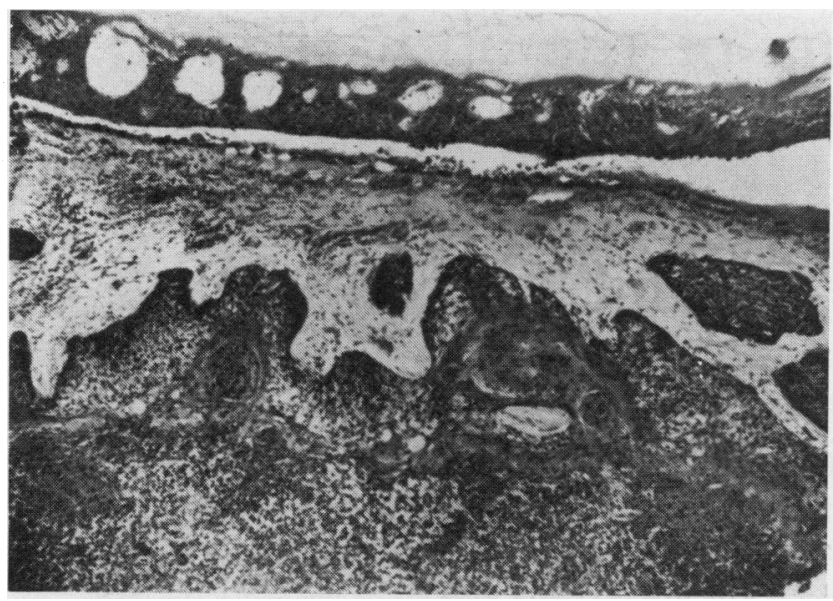

FIG. 3 Keratinizing squamous cell carcinoma in the choroid, showing degenerate peripheral retina at top. Haematoxylin and eosin. $\times 100$

I wish to thank Mr. Harris Tomkin, ophthalmic surgeon, for permission to report this case, Mr. J. S. R. Lavelle, F.R.C.S.I., for clinical and surgical information, and Mr. R. J. Lester, F.I.M.L.T., for technical assistance.

\section{Reference}

LARSEN, v. (1933) Acta ophthal. (Kbh.), II, $3^{86}$ 